\title{
Interfacial stereocomplexation to strengthen fused deposition modeled poly(lactide) welds
}

Varun Srinivas ${ }^{1,2}$, Catharina S.J. van Hooy-Corstjens², Gavin B.M. Vaughan ${ }^{3}$, Bas van Leeuwent, Sanjay Rastogi', Jules A.W. Harings ${ }^{1 *}$

${ }^{1}$ Aachen-Maastricht Institute for Biobased Materials, Maastricht University, P.O. Box

616, 6200 MD, Maastricht, The Netherlands. ${ }^{2}$ Zuyd University of Applied Sciences, P.O.

Box 550, 6400 AN, Heerlen. ${ }^{3}$ European Synchrotron Radiation Facility, CS40220,

38043 Grenoble, France. ${ }^{4}$ Corbion Purac Biomaterials, P.O. Box 21, 4200 AA

Gorinchem, The Netherlands.

*Corresponding author: jules.harings@maastrichtuniversity.nl 
S-2 
Table S1: Number average molecular weight $\left(M_{n}\right)$, Weight average molecular weight $\left(\mathrm{M}_{\mathrm{w}}\right)$ and Polydispersity (PDI) for PLLA and PDLA grades*

\begin{tabular}{cccc}
\hline Material & $\mathrm{M}_{\mathrm{n}}(\mathrm{kg} / \mathrm{mol})$ & $\mathrm{M}_{\mathrm{w}}(\mathrm{kg} / \mathrm{mol})$ & PDI \\
\hline PLLA245 & 117 & 245 & 2.1 \\
\hline PLLA190 & 90.5 & 190 & 2.1 \\
\hline PLLA148 & 72.0 & 148 & 2.1 \\
\hline PDLA100 & 47.5 & 100 & 2.1 \\
\hline PLLA100 & 50.0 & 100 & 2.0
\end{tabular}

* Determined by Gel Permeation Chromatography (GPC) using HFIP as the eluent and relative to Poly(MethyIMethAcrylate) (PMMA) 100k standards.

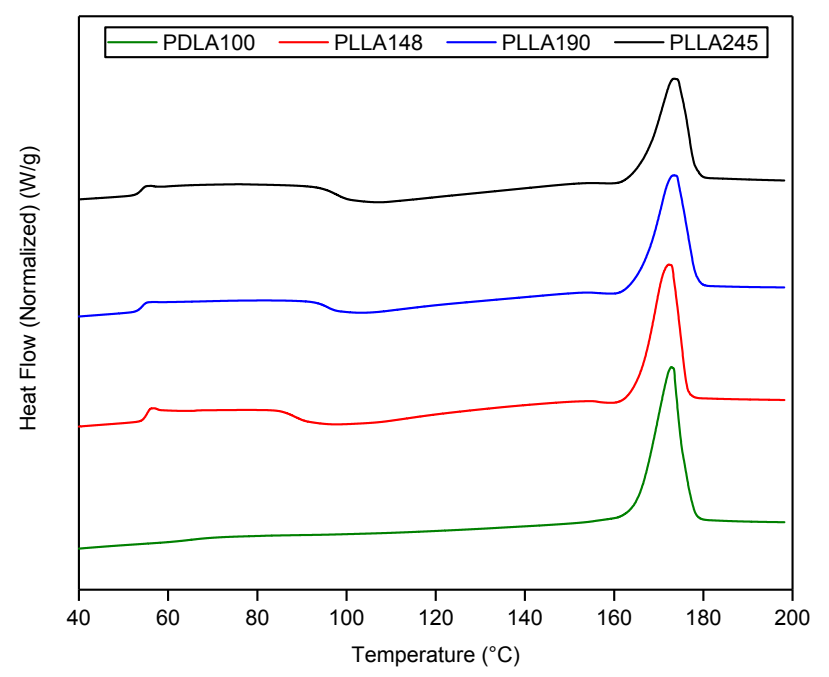

Figure S1: DSC thermograms of the as received PLLA245, PLLA190, PLLA148 and PDLA100 on heating at $10^{\circ} \mathrm{C} / \mathrm{min}$ from room temperature to $200^{\circ} \mathrm{C}$. 


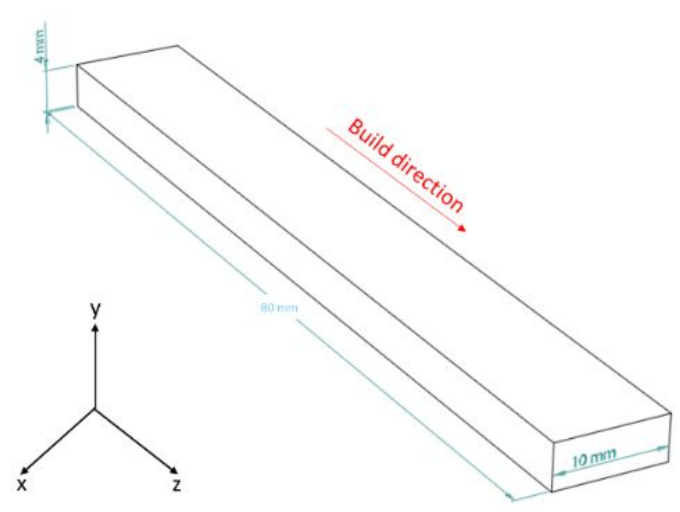

(a)

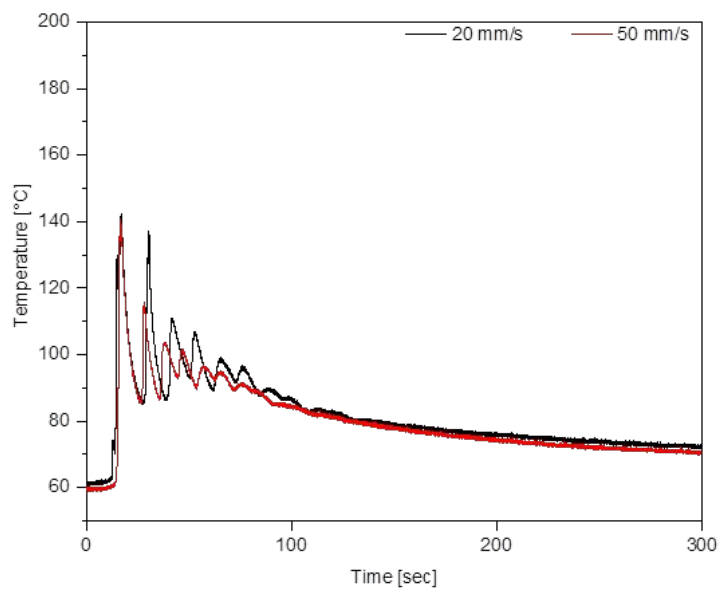

(b)

Figure S2: Schematic of sample geometry (a) and temperature of an ultrathin thermocouple placed under the bottom layer of the sample (b) upon printing at 20 (black) and $50 \mathrm{~mm} / \mathrm{s}$ (red).

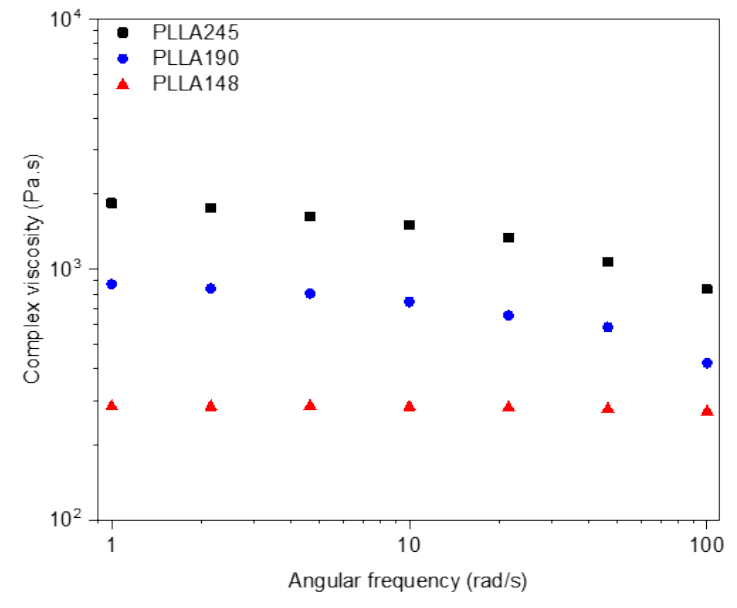

(a)

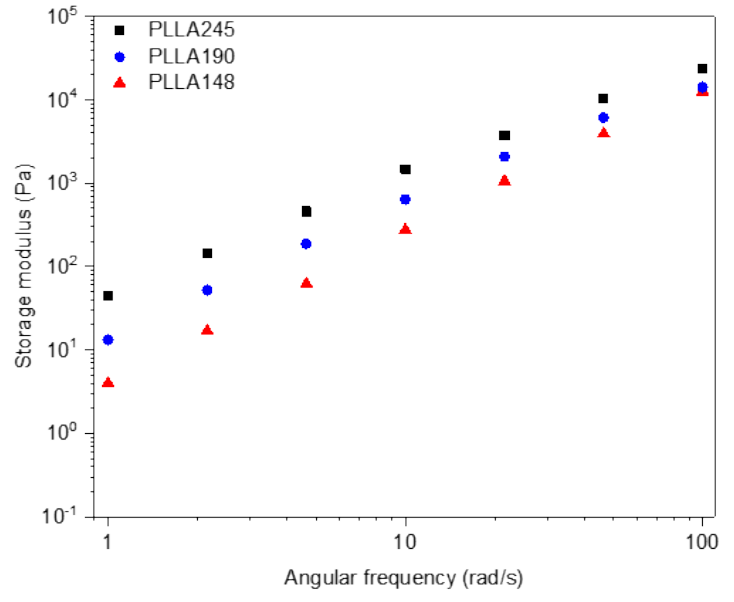

(b)

Figure S3: Complex viscosity (a) and storage modulus (b) of PLLA245, PLLA190 and PLLA148 plotted as a function of angular frequency. 


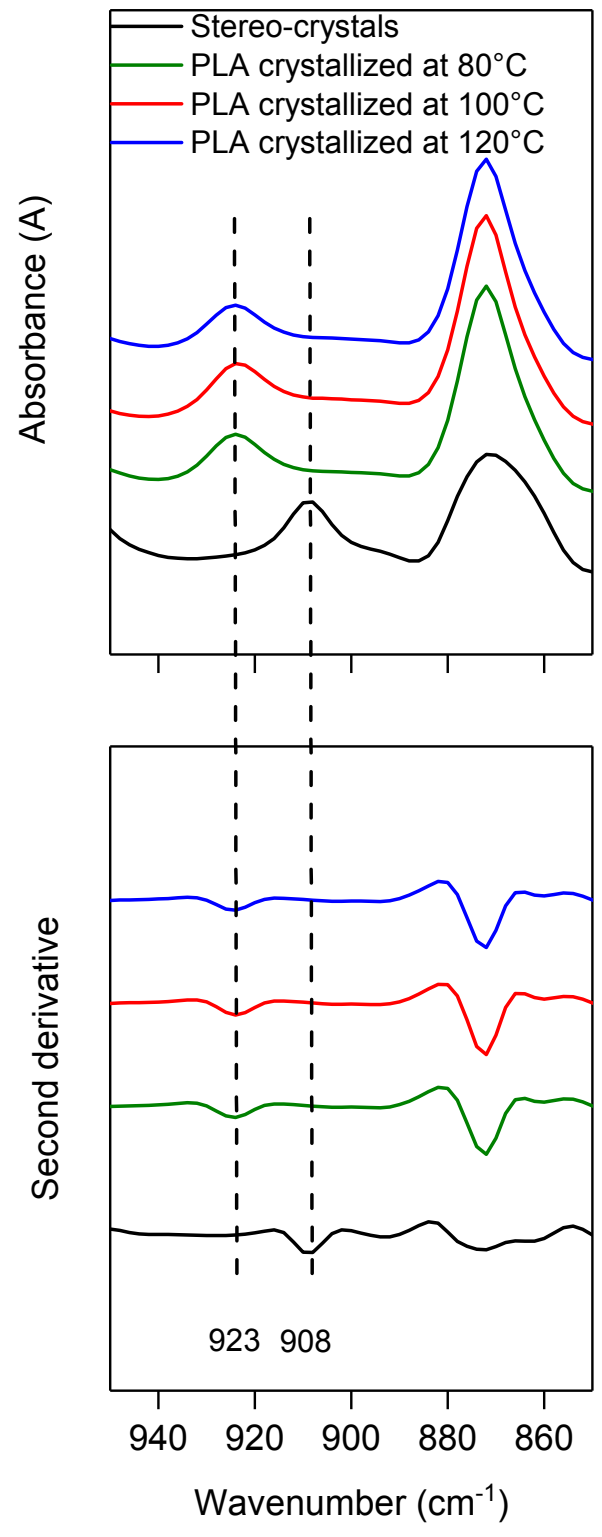


Figure S4: FTIR spectra and corresponding second derivative for PLLA148 and PDLA100 crystallized at $80^{\circ} \mathrm{C}, 100^{\circ} \mathrm{C}, 120^{\circ} \mathrm{C}$ and pure stereo-crystals. Samples crystallized at $80^{\circ} \mathrm{C}$, $100^{\circ} \mathrm{C}, 120^{\circ} \mathrm{C}$ represent homo-crystals and were produced by keeping a fully amorphous sample at the respective annealing temperature for 1 hour. On the other hand, stereocrystals were produced by keeping a 50:50 blend of PLLA148 and PDLA100 at $200^{\circ} \mathrm{C}$ for 15 minutes, after which the sample was quenched.

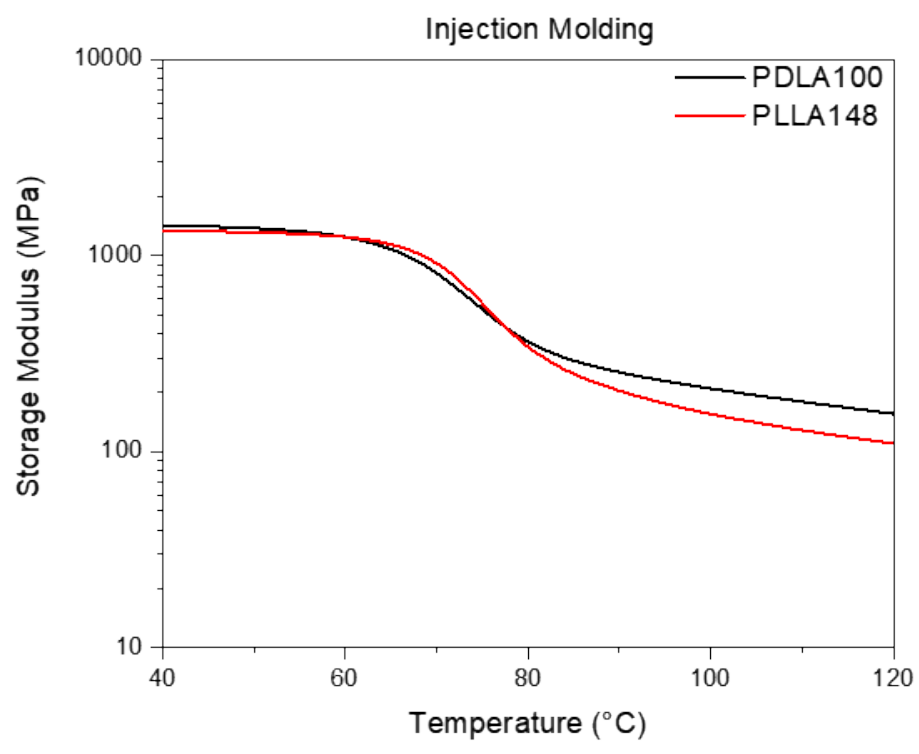

(a) 


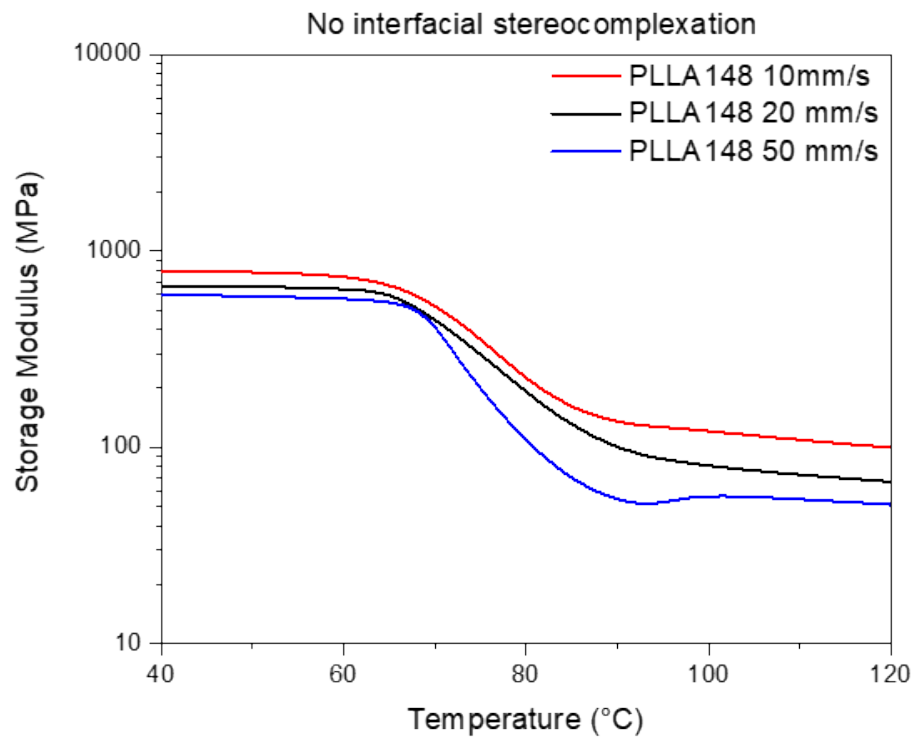

(b)

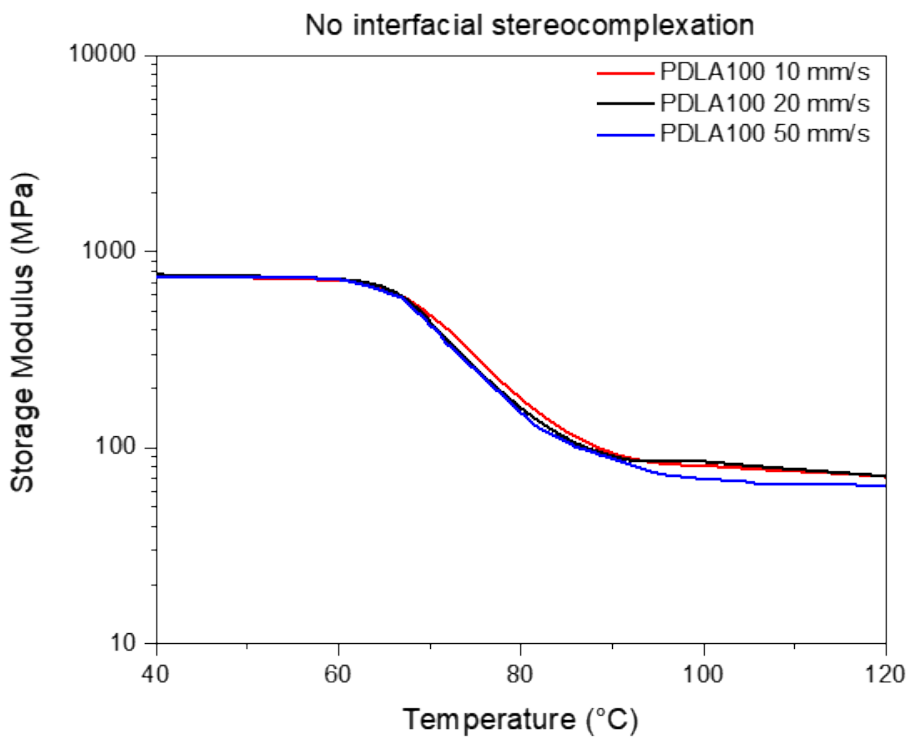

(c) 


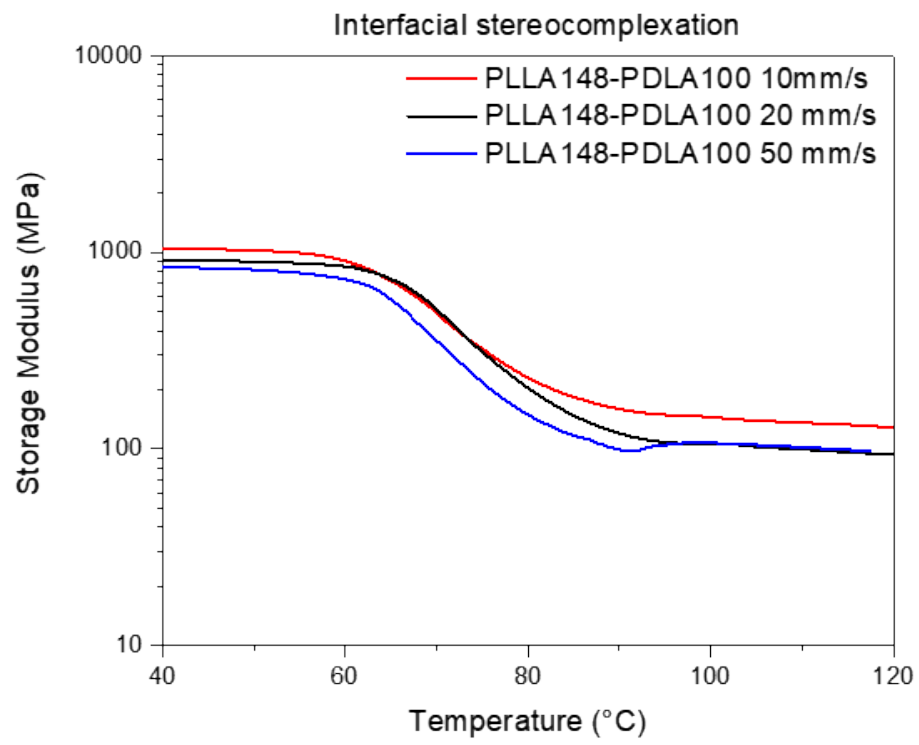

(d)

Figure S5: Storage modulus as a function of temperature for samples obtained via injection molding (a), samples with no interfacial stereocomplexation (b) and (c), samples with interfacial stereocomplexation (d). 